\title{
Apakah pelatihan keterampilan antarbudaya pada instansi pemerintahan dapat meningkatkan sensitivitas antarbudaya? Peranan nilai lokal gotong royong
}

\author{
Yanies Novira Soedarmadi \\ Program Studi Psikologi, Fakultas Bisnis, Psikologi \& Komunikasi, Universitas Teknologi Yogyakarta
}

\begin{abstract}
Abstrak
Terdapat inkonsistensi pada penelitian sebelumnya mengenai efek pelatihan keterampilan antarbudaya. Penelitian eksperimen ini bertujuan untuk meningkatkan sensitivitas antarbudaya melalui pelatihan keterampilan antarbudaya yang memasukkan materi tentang gotong royong sebagai nilai lokal Indonesia. Subjek penelitian berjumlah 32 orang yang dibagi menjadi 2 kelompok, yaitu 16 orang kelompok eksperimen dan 16 orang kelompok kontrol. Pelatihan keterampilan antarbudaya sebagai perlakuan. Pengukuran dilakukan sebelum dan setelah diberi pelatihan. Alat ukur yang digunakan adalah skala sensitivitas antarbudaya. Analisis data hasil penelitian menggunakan uji-t. Hasil penelitian menunjukkan terdapat perbedaan sensitivitas antarbudaya pada kelompok yang mendapatkan pelatihan keterampilan antarbudaya dengan kelompok yang tidak mendapatkan pelatihan $(t=2,063 ; p=0,048$; $\mathrm{p} \leq 0,05$ ). Selisih rerata pada kedua kelompok menunjukkan kelompok yang diberi perlakuan memiliki sensitivitas antarbudaya yang lebih tinggi (rerata $=7,38$ ).
\end{abstract}

Kata kunci: diversitas, pelatihan keterampilan antarbudaya, sensitivitas antarbudaya

\begin{abstract}
Previous works have been inconsistent in demonstrating the effectiveness of cultural diversity intervention. This experimental study aims to improve intercultural sensitivity through training in intercultural skills, with gotong royong (communal cooperation values) as local values. The research subjects were 32 participants who were divided into 16 participants in experimental groups and 16 participants in control groups. Intercultural skills training as a treatment. Measurements are made before and after training. The measuring instrument used is the intercultural sensitivity scale. Analysis of research data using the t-test. The results showed that there were differences in intercultural sensitivity in the group that received intercultural skills training with those who did not receive training $(t=2.063 ; p=0.048 ; p$ $\leq 0.05$ ). The mean difference between the two groups showed that the treated group had a higher intercultural sensitivity (mean $=7.38$ ).
\end{abstract}

Keywords: diversity, intercultural skills training, intercultural sensitivity

\section{Pendahuluan}

Hubungan antarbudaya yang disebut intercultural oleh Alred, Byram, dan Fleming, (2003) merupakan hal yang alamiah pada manusia dan dibawa sejak lahir. Indonesia memiliki keragaman budaya bangsa yang telah berusia berabad-abad dan berkembang melalui interaksi dan kerjasama antarbudaya. Bennet dan Bennet (2001) mendefinisikan diversitas dalam perspektif budaya sebagai perbedaan budaya dalam hal nilai, keyakinan, pembelajaran, maupun dipengaruhi oleh kelompok ketika berinteraksi yang mengacu pada pengidentifikasian diri berdasarkan pada perbedaan kebangsaan, etnisitas, gender, ras, karakter fisikal, dan pengelompokan lainnya.
Yu dan Chen (2008) mengungkapkan bahwa diversitas merupakan salah satu faktor penting dalam semakin cepatnya perkembangan teknologi, perpindahan penduduk, dan globalisasi ekonomi yang menyebabkan meningkatnya hubungan antarbudaya pada manusia baik dalam level individu dan organisasi. Badhesha, Schmidtke, Cummingss dan Moore (2008) menjelaskan pada telaah mengenai perilaku organisasi bahwa keanekaragaman atau diversitas budaya membawa sebuah kategorisasi sosial yang didasarkan pada perbedaan karakteristik demografi. Salah satunya, karakteristik yang bersifat dapat dilihat, lebih mudah diidentifikasi dan dapat dikategorisasi, misalnya, umur, jenis kelamin, dan ras. Kategorisasi secara sosial ini dapat membawa 
dampak sikap negatif terhadap orang dari luar kelompok.

Perbedaan budaya juga dapat memunculkan kesalahan persepsi (Hewstone, Rubin, \& Willis, 2002; Miller, 2008), reaksi emosional negatif (seperti prasangka), dan bentuk perilaku negatif seperti diskriminasi (Engberg, 2004). Purwaningsih, Galba, \& Ariani (2014) juga mencatat terdapat beberapa kasus konflik antarbudaya yang terjadi di Yogyakarta, seperti penyerbuan asrama mahasiswa Sumatera pada tahun 1970, perkelahian antarmahasiswa di daerah Seturan, Caturtunggal, Sleman yang berujung penyerbuan asrama mahasiswa Sulawesi Selatan pada tahun 2008, dan konflik antarwarga dengan mahasiswa asal NTT pada tahun 2013. Cox dan Blake (1991) menekankan pentingnya pemahaman, kemampuan untuk memaknai, mengelola, serta menghargai diversitas melalui tumbuh dan berkembangnya kesadaran dan sensitivitas terkait isuisu stereotip dalam lintas budaya. Salah satu dampak positif diversitas yang dikelola dengan tepat akan membawa keunggulan kompetitif baik dalam lingkup kehidupan ber-masyarakat maupun berorganisasi.

Mengelola isu-isu negatif diversitas budaya merupakan hal yang tidak ada habisnya untuk dikaji dan dicarikan solusi, mengingat Indonesia merupakan negara kepulauan dengan beragam suku, budaya, dan ras. Berkaca dari diversitas budaya yang belum terkelola dengan memadai, perlu digali cara-cara efektif untuk meningkatkan kemampuan individu menghadapi tantangan dalam lingkungan dengan diversitas budaya. Salah satu metode yang dapat digunakan adalah melalui pelatihan keterampilan antarbudaya. Pada penelitian eksperimen lapangan yang dilakukan oleh Roberson, Kulik, dan Pepper (2001), menyebutkan bahwa pelatihan antarbudaya efektif dalam meningkatkan kesadaran dan keterampilan mengelola isu-isu diversitas budaya seperti stereotip, prasangka, dan diskriminasi pada kelompok budaya yang berbeda. Keterampilan antarbudaya ini di antaranya terkait dengan kemampuan untuk berempati dan mengurangi bentuk-bentuk sikap negatif maupun stereotip. Paluck (2006) menyebutkan pelatihan diversitas memiliki isi ataupun materi yang berasal dari konsep teori yang bervariasi.

Akan tetapi, tidak selalu pelatihan semacam itu bisa meningkatkan sensitivitas antarbudaya (Vedantam, 2008). Dalam riset sebelumnya dicatat bahwa partisipan pelatihan merasa tidak nyaman, penuh dengan kategorisasi sosial yang membeda-bedakan, serta kontraproduktif (Hemphill \& Haines, 1997). Dikatakan bahwa butuh banyak faktor yang harus diperhitungkan jika ingin intervensi menghasilkan hasil pembelajaran yang diharapkan (Rynes \& Rosen,
1995). Analisis baru juga menunjukkan bahwa pelatihan keterampilan antarbudaya seringkali mengalami kegagalan bahkan bisa berakibat kebalikan dari hasil yang diinginkan (Dobbin \& Kalev, 2016). Oleh karena itu, penting untuk menguji kembali efektivitas dari pelatihan antarbudaya pada konteks yang berbeda. Dalam studi ini, pelatihan dilakukan dalam konteks partisipan instansi pemerintahan Indonesia. Sebagai kebaruan dari aspek intervensi, kami menambah konsep gotong royong yang unik dalam konteks budaya Indonesia.

\section{Pelatihan Keterampilan Antar Budaya}

Salah satu konsep yang digunakan pada pengelolaan diversitas oleh beberapa praktisi dan ahli sebelumnya dalam pelatihan antarbudaya adalah sensitivitas antarbudaya. Chen dan Starosta (1997) mengungkapkan konsep sensitivitas antarbudaya terdiri dari enam elemen interkultural yaitu self-esteem, self-monitoring, open-mindedness, interacting involvement, dan non-judgement. Penggunaan pelatihan keterampilan antarbudaya dengan mengikutsertakan aspek sensitivitas antarbudaya juga disebutkan oleh Graft (2004) dan Sizoo, Serrie, dan Shapero (2007) yang dilakukan dalam konteks kerja antarnegara guna penyesuaian budaya pada karyawan yang bekerja di luar negeri.

Penggunaan konsep sensitivitas antarbudaya masih jarang digunakan pada pelatihanpelatihan keterampilan antarbudaya, khususnya dalam konteks interaksi diversitas budaya di Indonesia. Pada penelitian ini, penggunaan materimateri dalam pelatihan yang memuat aspek-aspek konsep sensitivitas antarbudaya disusun dengan konteks budaya di Indonesia secara spesifik yang belum pernah digali dan dikembangkan sebelumnya. Salah satunya budaya gotong royong yang dapat mengembangkan empati dan keterlibatan dalam berinteraksi sosial (Wewengkang \& Moordiningsih, 2016). Nilai gotong royong sudah masuk sejak lama secara historis sehingga jangkar dalam meningkatkan sensitivitas komunal bisa memanfaatkan nilai lokal tersebut. Dengan kata lain, usaha pelatihan perlu memanfaatkan kearifan lokal agar efeknya bisa dipahami secara mudah.

Pelatihan keterampilan antarbudaya yang memuat konsep sensitivitas antarbudaya dilatihkan untuk mengembangkan kesadaran dan kepekaan terhadap diversitas budaya. Kesadaran dan kepekaan terhadap diversitas mampu menjadi sarana dalam interaksi antarkelompok budaya yang berbeda (Combs, 2002; Dong, Day, \& Colloco, 2007; Hewstone, Rubin, \& Willis, 2002; Paluck 2006; Spears, Oaks, Ellemers, \& Haslam, 1997). 
Chen dan Starosta (2000) mendefinisikan sensitivitas antarbudaya sebagai sebuah respon afektif berupa perasaan dan emosi terkait kesamaan dan perbedaan budaya. Rozaimie, Amelia, dan Aiza (2013) mengungkapkan kemampuan afektif seseorang terkait dengan budaya dapat membantu individu untuk menghadapi hambatan menghadapi interaksi antarbudaya dan konflik lintas budaya. Individu yang memiliki sensitivitas antarbudaya dalam menghadapi situasi maupun interaksi antarbudaya mendukung penyesuaian lintas budaya.

Studi yang dilakukan oleh Chen dan Starosta (2000) menunjukkan individu yang memiliki sensitivitas antarbudaya yang tinggi cenderung akan lebih perhatian, lebih cakap dalam menerima sisi sosial-interpersonal individu lain saat menjalin hubungan dalam usahanya untuk menyesuaikan diri dengan perilaku orang yang berbeda budaya, menunjukkan harga diri yang tinggi, kemampuan mengontrol diri, serta lebih empati dan efektif dalam menjalin interaksi antarbudaya.

Aspek-aspek dalam sensitivitas antarbudaya dihadirkan melalui terciptanya insight mengenai kesadaran nilai-nilai diversitas dan insight sosial-emosional terkait perbedaan budaya, terdapat juga pemahaman yang mendalam terkait aspek-aspek sensitivitas antarbudaya. Metode yang digunakan dalam pelatihan ini sebagian besar adalah metode eksperiensial berbentuk role-play dan dikombinasikan dengan metode instruksional seperti ceramah, menonton cuplikan film, dan latihan. Penelitian ini bertujuan untuk memecahkan persoalan mengenai apakah pelatihan keterampilan antarbudaya dapat meningkatkan sensitivitas antarbudaya dalam upaya mengelola diversitas budaya yang ada. Hipotesis yang diajukan dari penelitian ini adalah pelatihan keterampilan antarbudaya berpengaruh dalam meningkatkan sensitivitas antarbudaya.

\section{Metode Penelitian}

\section{Partisipan}

Penelitian ini diikuti oleh 32 orang partisipan yang bekerja pada beberapa instansi pemerintahan dan berinteraksi serta bekerja sama di dalam lingkungan yang memiliki diversitas budaya setiap harinya. Terdiri dari 5 orang laki-laki dan 27 orang perempuan. Masing-masing partisipan dibagi menjadi dua kelompok, yaitu 16 orang partisipan pada kelompok eksperimen dan 16 orang partisipan pada kelompok kontrol. Pelaksanaan pemilihan partisipan tidak dilakukan secara random karena keterbatasan waktu dari masing-masing peserta yang berbeda instansi untuk mengikuti kegiatan pelatihan.

\section{Pengukuran}

Instrumen penelitian ini menggunakan skala sensitivitas antarbudaya yang diciptakan oleh Chen dan Starosta (2000) dan dikembangkan oleh Fritz dan Chen (2002) yang kemudian disesuaikan ke dalam bahasa Indonesia dan diujicobakan kembali oleh peneliti sehingga didapatkan 18 aitem sahih. Koefisien korelasi aitemtotal yang memenuhi persyaratan berkisar antara 0,324-0,673 dan koefisien reliabilitas skala sensitivitas antarbudaya sebesar $\alpha=0,856$.

\section{Desain}

Para partisipan dengan menggunakan desain quasi experiment yang disebut the untreated control group design with dependent pretest and posttest (Shadish, Cook, \& Campbell, 2002). Pada desain eksperimen ini, terdapat kelompok eksperimen yang akan diberikan perlakuan berupa pelatihan keterampilan antarbudaya dan kelompok kontrol sebagai kelompok pembanding yang tidak diberi perlakuan. Pengaruh efek dari perlakukan diukur dengan membandingkan keadaan variabel tergantung berupa sensitivitas antarbudaya pada kelompok eksperimen dan kelompok kontrol. Desain eksperimen pada penelitian ini tergambar pada Gambar 1.

\section{Prosedur}

Prosedur penelitian terdiri dari seluruh rangkaian penelitian yang dimulai dari penjajakan awal penelitian. Pengukuran diberikan sebelum hingga setelah perlakuan diberikan kepada partisipan penelitian. Partisipan yang bersedia mengikuti rangkaian penelitian telah mengisi lembar kesediaan dan persetujuan untuk mengikuti seluruh tahapan penelitian. Perlakuan dalam penelitian ini berupa pelatihan keterampilan antarbudaya yang mengacu pada konsep sensitivitas antarbudaya yang dikembangkan oleh Chen dan Starosta (1997). Konsep sensitivitas antarbudaya yang dilatihkan pada sesi-sesi pelatihan keterampilan antarbudaya terdiri dari self-esteem, self-monitoring, keterbukaan pikiran, empati, keterlibatan dalam interaksi, dan tidak terburu-buru dalam memberikan penilaian terhadap orang dari budaya yang berbeda. 
Gambar 1.

Desain eksperimen

\begin{tabular}{cccc} 
(NR) KE & 0 & $X$ & $O_{2}$ \\
\hline (NR) KK & $\mathrm{O}_{1}$ & & $0_{2}$
\end{tabular}

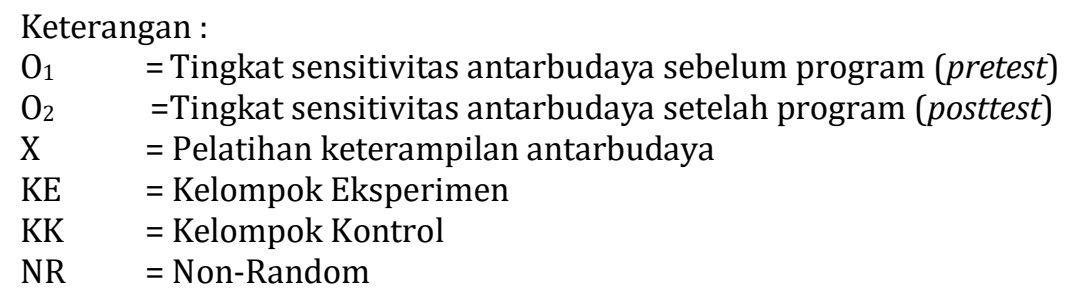

Sesi-sesi pada pelatihan keterampilan antarbudaya terdiri atas empat sesi. Sesi pertama, yaitu sesi pembuka, bertujuan untuk mencairkan suasana dan mempersiapkan peserta mengikuti pelatihan. Sesi kedua berisi role-play bermain peran dalam kegiatan permainan bafa-bafa yang selanjutnya diikuti dengan kegiatan ceramah serta diskusi. Role-play bafa-bafa ditujukan untuk menghadirkan kesadaran diri tentang diversitas budaya dan insight partisipan mengenai konsep sensitivitas antarbudaya. Bhawuk dan Brislin (2000) menjelaskan bahwa role-play bafa-bafa dapat menciptakan insight antarbudaya dan interaksinya mampu melibatkan partisipan secara emosional dan kognitif. Selanjutnya, metode ceramah serta diskusi digunakan untuk memberikan pengetahuan dan pemahaman terkait konsep sensitivitas antarbudaya kepada partisipan. Sesi ketiga, yaitu, pendalaman aspek-aspek sensitivitas antarbudaya yang ditujukan untuk memberikan pemahaman terkait aplikasi konsep sensitivitas antarbudaya dalam kehidupan sehari-hari. Kegiatan pada sesi ketiga terdiri dari role-play bergotong royong menyusun puzzle budaya, latihan menulis self-report saat berinteraksi antarbudaya, penyajian tayangan audiovisual tentang diversitas budaya, ceramah, serta diskusi tentang kegiatan yang dilakukan pada sesi ketiga. Sesi keempat, yaitu, sesi penutup berisi kesimpulan dari pelatihan dan pengisian lembar evaluasi proses pelatihan.

\section{Teknik Analisis}

Data penelitian dianalisis dengan menggunakan statistika parametrik berupa uji-t. Siegel (1956) menyebutkan uji-t dapat menjadi pengukuran yang kuat apabila terpenuhi kondisi populasi terdistribusi normal dan homogen. Setelah data pre-test pada kelompok eksperimen dan kelompok kontrol dinyatakan normal dan homogen, uji-t digunakan untuk menguji hipotesis.
Taraf signifikansi yang digunakan dalam uji-t adalah pada level 5\% ( $\leq \leq 0,05)$.

\section{Hasil Penelitian}

Berdasarkan analisis data, pada kelompok eksperimen dan kelompok kontrol sebelum diberikan perlakuan terdistribusi normal dengan nilai $\mathrm{Z}=$ $0,728$ ( $p>0,05)$. Data juga ternyata homogen dengan nilai $F=1,174(p>0,05)$. Pengujian hipotesis menggunakan uji-t untuk melihat perbedaan tingkat sensitivitas antarbudaya antara kelompok eksperimen dan kelompok kontrol sebelum dan setelah pemberian pelatihan keterampilan antarbudaya.

Hasil eksperimen menunjukkan bahwa nilai p pada saat pre-test adalah 0,48 . Hal tersebut menjelaskan bahwa rerata skor sensitivitas antarbudaya pada kelompok eksperimen sebesar 69,81 dan kelompok kontrol sebesar 71,69 yang berarti tidak terdapat perbedaan secara signifikan pada saat sebelum pelaksanaan intervensi pelatihan sensitivitas antarbudaya. Pada saat post-test, didapatkan skor rerata sensitivitas antarbudaya pada kelompok eksperimen sebesar 77,19 dan kelompok kontrol sebesar 71,88. Berdasarkan hasil tersebut, dapat disimpulkan bahwa rerata skor sensitivitas antarbudaya kelompok eksperimen lebih tinggi daripada kelompok kontrol setelah diberikan pelatihan keterampilan antarbudaya.

Berdasarkan hasil perhitungan uji independent sample t-test pada sensitivitas antarbudaya, diperoleh nilai $t(30)$ sebesar 2,063 berbeda secara signifikan pada $(\mathrm{p} \leq 0,05)$. Artinya terdapat perbedaan skor sensitivitas antarbudaya yang signifikan pada kelompok eksperimen dan kelompok kontrol setelah pemberian pelatihan keterampilan antarbudaya. Dengan kata lain, dapat disimpulkan bahwa pelatihan keterampilan antarbudaya berpengaruh signifikan pada sensitivitas antarbudaya. 
Gambar 2

Perbandingan Rerata Skor Sensitivitas Antarbudaya Kelompok Eksperimen dan Kelompok Kontrol Sebelum dan Sesudah Pelatihan Keterampilan Antarbudaya

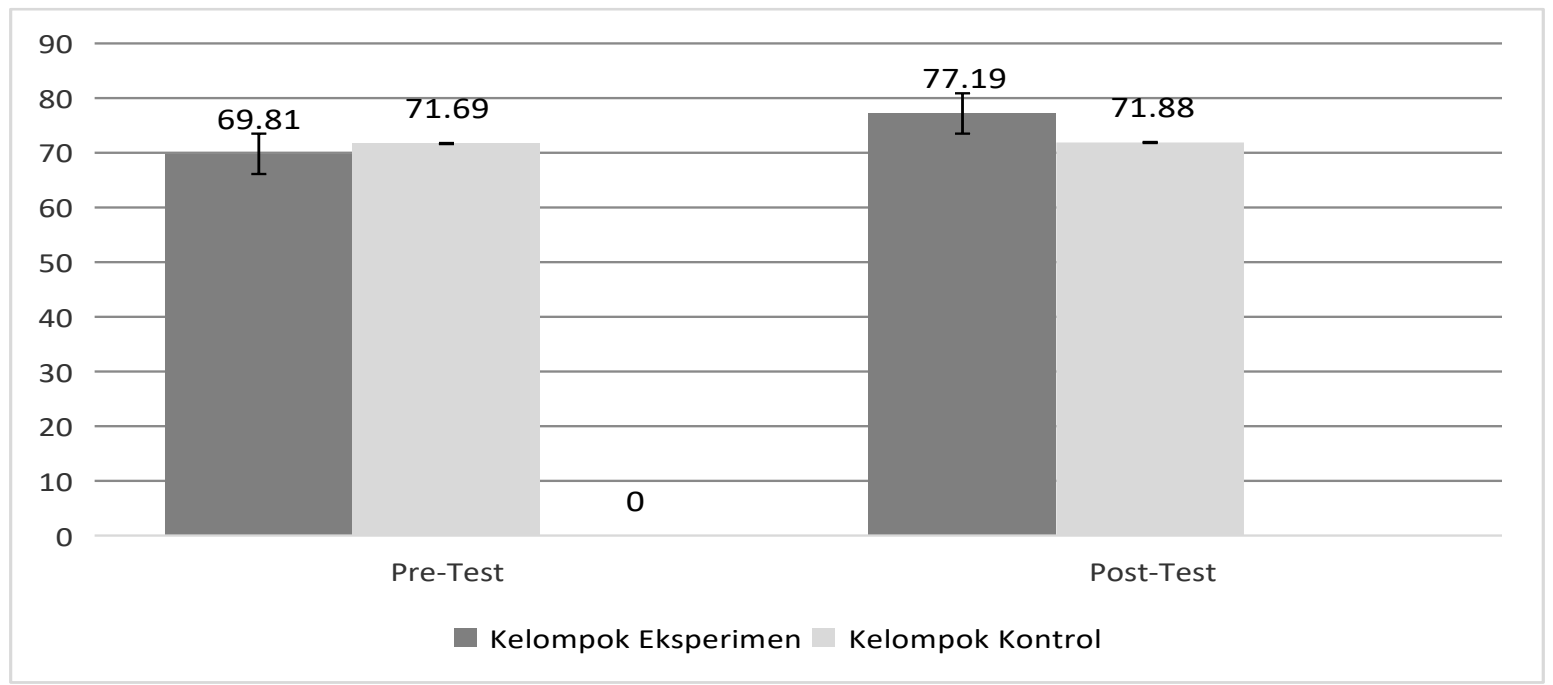

\section{Diskusi}

Berdasarkan hasil analisis data, terdapat perbedaan signifikan, yaitu, $\mathrm{p}=0,048(\mathrm{p} \leq 0,05)$ pada skor rerata sensitivitas antabudaya kelompok yang diberikan perlakuan, yaitu kelompok eksperimen dengan kelompok yang tidak diberi perlakuan, yaitu kelompok kontrol. Artinya perlakuan yang diberikan pada kelompok eksperimen berupa pelatihan keterampilan antarbudaya dapat meningkatkan sensitivitas antarbudaya. Hasil penelitian ini sejalan dengan penelitian yang melibatkan sensitivitas interkultural pada pelatihan diversitas antarbudaya seperti dilaporkan dalam penelitian Roberson, dkk. (2001), Sizoo, dkk. (2007), dan Paluck (2006). Ada pula tambahan materi tentang gotong royong dimana ini menjadi nilai lokal yang masuk sebagai materi. Riset ini menunjukkan bahwa peranan nilai lokal mungkin penting dalam efektivitas pelatihan keterampilan antarbudaya.

Bennet dan Bennet (2001) menyebutkan pelatihan keterampilan antarbudaya yang mencakup sensitivitas antarbudaya mampu membuat interaksi antarbudaya menjadi lebih efektif dengan menumbuhkan kesadaran diri seseorang sehingga tidak mudah terbawa stereotip, mampu bertoleransi dan memahami hal-hal terkait ambiguitas budaya pada kelompok budaya yang berbeda dan beragam. Pelatihan keterampilan antarbudaya pada penelitian ini mengusahakan hadirnya enam elemen sensitivitas antarbudaya yaitu self-esteem, self-monitoring, open-mindedness atau keterbukaan pikiran, empati, keterlibatan dalam interaksi, dan tidak terburu-buru dalam mem- berikan penilaian terhadap orang dari budaya yang berbeda. Self-esteem dan self-monitoring dalam pendekatan individual berhubungan dengan motivasi yang dimiliki seseorang dalam menilai maupun mengarahkan tindakan terhadap orang dari kelompok budaya berbeda. Pengembangan self-esteem dan self-monitoring dilakukan dengan mengembangkan motivasi seseorang melalui hadirnya kesadaran akan diversitas. Insight yang menghadirkan kesadaran diversitas dan hal-hal yang dibawa juga menjadi kunci pengembangan elemen selanjutnya, yaitu, open-mindedness dan non-judgement. Hadirnya insight mengenai diversitas budaya akan mendorong seseorang untuk dapat memiliki persepsi yang objektif dengan memahami bahwa setiap individu adalah unik, sehingga mereka dapat berpikir lebih objektif dan terbuka terhadap perbedaan pandangan.

Empati juga dikembangkan melalui hadirnya insight sosial-emosional yang melibatkan pemahaman atas perasaan orang lain yang dapat berupa cara pangambilan sudut pandang dan komunikasi ketika berinteraksi. Aspek keterlibatan interaksi terkait dengan kontak antar kelompok yang mana melalui interaksi dan kerja sama akan membantu meningkatkan pengetahuan dan empati terhadap orang lain. Seseorang juga dapat belajar memahami dan perhatian terhadap situasi yang dihadapi oleh orang lain. Rasmussen, Llyod, dan Wielundt (2005) mengungkapkan individu yang memiliki sensitivitas budaya dapat terlihat dari cara seseorang berkeyakinan, bersikap, berperilaku, gaya hidup, serta cara ia bekerja. 
Intervensi berupa pelatihan keterampilan antarbudaya mampu meningkatkan sensitivitas antarbudaya dengan tumbuhnya kesadaran dan pemahaman mengenai diversitas budaya sehingga individu mampu mengevaluasi dan memberikan penilaian yang lebih objektif terhadap orang atau kelompok budaya tertentu. Berdasarkan pengetahuan dan pemahaman yang dimiliki, diharapkan individu berinteraksi dan berkomunikasi dengan lebih baik. Crisp (2010) menjelaskan bahwa dalam sejarah tidak ada negara atau bangsa yang mampu menghilangkan perbedaan antarkelompok. Usaha dalam menghilangkan perbedaan ini hanya akan menjadi sumber konflik dan bias persepsi. Indonesia dengan diversitas yang ada tersebar di seluruh wilayah Negara Kepulauan Republik Indonesia tidak mungkin dapat dihilangkan, namun selayaknya dikelola sehingga dapat menjadi keunggulan kompetitif dalam memperkuat posisi negara di kancah internasional dan diharapkan mampu membawa dampak pada kesejahteraan masyarakatnya.

Penelitian ini juga memerlukan follow-up atau evaluasi setelah post-test sehingga penelitian ini tidak hanya dapat melihat efektivitas pelatihan dalam jangka pendek saja, namun juga jangka panjang. Crisp (2010) juga menjelaskan bahwa pelatihan terkait perbedaan antarbudaya sebaiknya diikuti oleh kegiatan yang melibatkan organisasi, seperti, mentoring ataupun action plan terkait pengembangan kemampuan antarbudaya.

\section{Kesimpulan}

Berdasarkan penelitian yang telah dilakukan dapat ditarik kesimpulan bahwa pelatihan keterampilan antarbudaya ini dapat meningkatkan tingkat sensitivitas antarbudaya. Kelompok yang mendapatkan pelatihan keterampilan antarbudaya menunjukkan tingkat sensitivitas antarbudaya yang lebih tinggi.

Penelitian selanjutnya dapat mengembangkan penelitian dengan melihat efek jangka panjang pelatihan keterampilan antarbudaya terhadap sensitivitas antarbudaya, serta mengumpulkan umpan balik terkait bagaimana keterampilan antarbudaya tersebut diaplikasikan dalam bentuk perilaku oleh partisipan di lingkungannya.

\section{Daftar Pustaka}

Alred, G., Byram, M., \& Fleming, M. (2003). Intercultural experience and education. Cromwell Press.

Bandhesha, S. R., Schmidtke, J. M., Cummings, A., \& Moore, S.C. (2008). The effects of diversity training on specific and general atitudes toward diversity. Multicultural Education \&
Technology Journal, 2, 87-106. https://doi.org/10.1108/175049708108833 60

Bennett, J. M. \& Bennett, M.J. (2001, June). Developing intercultural sensitivity: An integrative approach to global and domestic diversity. [Simposium]. The Diversity Symposium 2001. The Diversity Collegium Membership Meeting, Oregon, Amerika Serikat.

Bhawuk, P. S. \& Brislin, R.W. (2000). Crosscultural training: A review. Delhi Business Review. 1(1). 1-20. http://dbr.shtr.org/v_1n1/dbrv1n1b.pdf

Chen, G. M. \& Starosta, W. J. (2000). The developmental and validation of the intercultural communication sensitvity scale. Human Communication, 3, 1-15. https://digitalcommons.uri.edu/cgi/viewcon tent.cgi?article $=1035 \&$ context $=$ com_facpubs

Chen, G. M. \& Starosta, W. J. (1997). A review of the concept of intercultural sensitivity. Human Communication, 1(1), 1-16. https://digitalcommons.uri.edu/cgi/viewcon tent.cgi?article $=1037 \&$ context $=$ com_facpubs

Combs, G. M. (2002). Meeting the leadership challenge of a diverse and pluralistic workplace: Implications of self-efficacy for diversity training. Journal of Leadership \& Organizational Study, 8, 1-16. https://doi.org/ 10.1177/107179190200800401

Cox, T. H \& Blake, S. (1991). Managing cultural diversity: Implications for organizational competitiveness. Academy of Management Executive, 5 (3), 45-56. https://www.jstor.org/stable/4165021?seq $=1 \#$ metadata_info_tab_contents

Crisp, R. J. (2010). The psychology of social and cultural diversity. Wiley-Blackwell.

Dobbin, F., Kalev, A. (2016). Why diversity programs fail. Harvard Business Review, 94(7/8), 52-60. Retrieved from https://hbr.org/2016/07/whydiversity-programs-fail

Dong, Q., Day, K. D., \& Collaco, C. M. (2007). Overcoming ethnocentrism through developing intercultural communication sensitivity and multiculturalism. Human Communication. $11 \quad$ (1). 27-38. https://pdfs.semanticscholar.org/3208/817 843de2f921a5ff9cd1780fab5308deeb7.pdf? ga $=2.265558799 .1473412099 .1584277347$ 1142890522.1584161452

Ellemers, N., Gilder, D. D., \& Haslam S. A. (2004). Motivating individuals and groups at work: A social identity perspective on leadership and group performance. Academy of Management $\begin{array}{llll}\text { Behavior. } & 20 & \text { (3). } & 450-478 .\end{array}$ 
https://research.vu.nl/ws/portalfiles/portal /1953449/Ellemers+Academy+of+Managem ent+Review+29\%283\%29+2004+u.pdf

Engberg, M. E. (2004). Improving intergroup relations in higher education: A critical examination of the influence of educational interventions on racial bias. Review of Educational Research, 74 (4), 473-524. https://doi.org/ 10.3102/00346543074004473.

Fritz, W., Mollenberg, A., \& Chen, G. M. (2002). Measuring intercultural sensitivity in different cultural context. Intercultural Communication Studies, 11, 165-176. https://digitalcommons.uri.edu/cgi/viewcon tent.cgi?article $=1019 \&$ context $=$ com_facpubs

Graf, A. (2004). Assesing intercultural training designs. Journal of European Industrial Training, 28 (2/3/4), 199-214. https://doi. org/10.1108/03090590410527618

Hemphill, H., \& Haines, R. (1997). Discrimination, harassment, and the failure of diversity training: What to do now. Greenwood Publishing Group.

Miller, S. L. (2008). Self-protective bias in group categorization what shapes the psychological boundary between "us" and "them"? [Tesis magister, Florida State University]. Diakses melalui

https://www.researchgate.net/publication/ 254672457 Self-

Protective Biases In Group Categorization What Shapes_The_Psychological_Boundary Between_Us_And_Them

Hewstone, M., Rubin, M., \& Willis, H. (2002). Intergroup bias. Annual Review Psychology, 53, 575-604. https://doi.org/10.1146/annurev.psych.53.1 00901.135109

Paluck, E. L. (2006). Diversity training and intergroup contact: A call to action research. Journal of Social Issues. 62 (3). 577-595. https://static1.squarespace.com/static/518 6d08fe4b065e39b45b91e/t/51e32409e4b0 ebae3ad1c13a/1373840393551/Paluck+20 06.pdf

Purwaningsih, E., Galba, D., \& Ariani, C. (2014). Interaksi penghuni asrama mahasiswa dengan masyarakat sekitar: Suatu pijakan awal multikulturalisme (Kasus lima asrama mahasiswa di Yogyakarta). Balai Pelestarian Nilai Budaya (BPNB) Yogyakarta.

Rasmussen, T., Lloyd, C., \& Wielandt, T. (2005). Cultural awareness among Quensland undergraduate occupational therapy students. Australian Occupational Therapy Journal, 52(4), 302-310. https://doi/abs/10.1111/j.14401630.2005.00508.x

Roberson, L, Kulik, C. T., \& Pepper, M. B. (2001). Designing effective diversity training: Influence of group composition and experience. Journal of Organization Behavior. $22 \quad$ (8). 871-885. https://doi.org/10.1002/job.117

Rozaimie, A. A, S., Amelia, A.T., \& Aiza, J. (2013). Intercultural sensitivity and cross-cultural adjustment among Malaysian student abroad. Journal of Educational and Social Research. 3(7). https://10.5901/jesr.2013.v3n7P6393.

Rynes, S., \& Rosen, B. (1995). A field survey of factors affecting the adoption and perceived success of diversity training. Personnel Psychology, 48(2), 247-270. https://doi.org/10.1111/j.17446570.1995.tb01756.x

Shadish, W. R,, Cook, T. D., \& Campbell, D. T. (2002). Experimental and quasi-experimental design for generalized causal inference. Houghton Mifflin Company.

Sizoo, S., Serrie, H., \& Shapero, M. (2007). Revisiting a theory-supported approach to teach cross-culture management skills. Journal of Teaching in International Business, , 18(2-3),

83-99. https://www.tandfonline.com/doi/abs/10.1 300/J066v18n02_05

Spears, R,, Oakes, P. J., Ellemers, N., \& Haslam, S. A. (1997). The social psychology of stereotyping and group life. Blackwell Publisher.

Vedantam, S. (2008). Most diversity training ineffective, study finds. The Washington Post.

Wewengkang, D. B. P., \& Moordiningsih. (2016). Studi fenomenologi konteks budaya Jawa dan pengaruh Islam: Situasi psikologis keluarga dalam membangun empati pada remaja. Jurnal Indigenous, 1 (1), 1-11. https://doi.org/10.23917/indigenous.v1i1.3 129

Yu, T. \& Chen, G. M. (2008). Intercultural sensitivity and conflict management style in cross-culture organization situations. Intercultural Communication Studies, 17, 149161.

https://digitalcommons.uri.edu/cgi/viewcon tent.cgi?article $=1030 \&$ context $=$ com_facpubs 